\title{
Effect of Amylose-Amylopectin Ratio on the Structure of Starch Granules of Selected Rice Varieties
}

\author{
Neethu Ravikumar1* and K. Anooja Thomas ${ }^{2}$ \\ 'Research Scholar, Department of Home Science, St. Theresas College, \\ Ernakulam, India; ravikumar.neethu@gmail.com \\ ${ }^{2}$ Associate Professor, Department of Home Science, CMS College, \\ Kottayam, India; anoojam@gmail.com
}

\begin{abstract}
Amylose content is considered to be one of the most important quality traits which affect both the processing and cooking characteristics of rice. In the present study two types of rice cultivars were used "Cheruvally and D1" to investigate the influence of amylose-amylopectin ratio on the granular structure of starch. Both varieties were cold soaked (12 hours) and hot soaked $\left(70^{\circ} \mathrm{C}\right.$ for 3 hours). Amylose content was determined spectrophotometrically and morphological characteristics of starch granules were determined by Scanning Electron Microscopy (SEM). Data collected were tabulated and consolidated. The density of cold and hot soaked paddy had increased and among the rice varieties analyzed for amylose content, the total amylose content ranges in the order of Cold soaked $>$ Hot soaked $>$ Raw paddy. The SEM Micrograph revealed that the granular structure was lost for both cold soaked and hot soaked rice varieties due to hydration and heating.
\end{abstract}

Keywords: Amylose:amylopectin Ratio, Morphology, Scanning Electron Microscopy, Starch Granules

\section{Introduction}

According to FAO (2005) rice is considered second to wheat in terms of annual production as food [1]. Starch is the most abundant carbohydrate and important polymer both to plants and animals, second to cellulose. Starch is a mixture of two glucans namely amylose and amylopectin [2]. Amylose is a linear polymer, with $\alpha$ - $(1,4)$-linkage while amylopectin is highly branched and made up of $\alpha-(1,4)$ and $\alpha-(1,6)$ linkages [3]. Gelatinization of starch is a phase transition of granular structure of starch from an ordered to a disordered state during heating with excess water. It induces a number of changes such as swelling of starch granules, transudation of amylose and amylopectin, distortion of starch granule, loss of birefringence, and increased viscosity [4]. Since loss of birefringence occurs at the time of initial rapid gelatinization (granular swelling), birefringence loss is considered to be a good indicator of the gelatinization temperature of a given starch. Amylose ceases gelatinization because it diffuses out of the granules during swelling, make up the continuous phase (network) outside the granules [5]. Ultimately granule structure is completely lost and a thin paste $(<\sim 4 \%)$ or gel $(>\sim 4 \%)$ is formed. Evidence of this loss of ordered state can be seen by irreversible granular swelling, loss of birefringence, and loss of crystalline structure of starch. Quantifying gelatinization characteristics of food is very relevant in food processingbecause it simulate the cooking process thereby improving the functionalcharacteristics of starch [6]. The study was aimed to determine the effect of amylose-amylopectin ratio on the structure of starch granules of six samples selected (Raw D1 and Cheruvally; Cold Soaked D1 and Cheruvally; Hot Soaked D1 and Cheruvally). Raw rice cultivars were selected as control samples and cold soaked samples were prepared by soaking in water for 12 hours followed by sun drying. The

${ }^{*}$ Author for correspondence 
hot soaked varieties were prepared by subjecting the raw ones to $70^{\circ} \mathrm{C}$ for 3 hours followed by sun drying.

\section{Methodology}

Two rice varieties - "D1and Cheruvally" were procured from Rice Research Station, Monkompu, Kerala. The paddy collected for the study were cleaned manually for removing any debris and were subsequently cold soaked ( 12 hours), hot soaked $\left(70^{\circ} \mathrm{C}\right.$ for 3 hours), steamed and dried in sun. Grain samples were milled for $30 \mathrm{sec}-$ onds to remove the husk. The amylose content of the rice samples was determined spectrophotometrically at 620 $\mathrm{nm}$ and their structures were revealed through SEM.

\section{Results}

\subsection{Assessment of Total Amylose Content}

Amylose content in rice is considered as an objective index for cooked rice texture and is and an important factor which influences the cooking and processing characteristics of rice [7]. In the present study among the rice varieties analyzed for amylose content, the maximum total amylose content of raw rice was observed as $25.7 \%$ for the variety D1, followed by the Cheruvally (25.2\%). But after conversion of raw paddy into parboiled one, an increase in total amylose content was observed. The difference in amylose content was found to be high when a comparison is made between Cold Soaked varieties (Cold Soaked D1 27.8\% and Cold Soaked Cheruvally 27.7\%) and control samples (Raw D1 25.7\% and Raw Cheruvally $25.2 \%)$. Paddy varieties chosen for sampling belong to high amylose content variety as described by Lawal et al [2] and maximum amylose content was observed for cold soaked samples (D1- 27.8\% and Cheruvally 27.7\%) than hot soaked ( D1 26.8\% and Cheruvally 26.1\%) and raw one. The difference in amylose content was found to be high when a comparison is made between cold soaked and raw rice cultivars. Theratio of amylose to amylopectin is an important property of rice which determines its quality during processing and cooking [8]. Rice starches with high amylose - amylopectin ratio will readily absorb more water during boiling and become fluffy with separate grains on cooking. In the present study the ratio of cold soaked, hot soaked and control samples were found to be in the range of 0.34-0.39 (Table 1).

\subsection{Determination of Starch Structure by Scanning Electron Microscope}

The SEM Micrograph of each sample was taken on $5 \mu \mathrm{m}$ scale (Figure 1-6). Both the strands and starch granules can be easily distinguished in case of raw forms of both Cheruvally and D1. While observing the Hot Soaked varieties, the granular structure was lost which was due to the influence of both heat and water. But in the case of Cold Soaked rice cultivars the granular structure seems to be more coagulated. This was mainly due to prolonged water absorption by the cold soaked ones (soaking for 12 hours) which resulted in granular swelling. Thus from the SEM Micrograph of both control and treated samples it can be revealed that the starch will loose its granular structure due to hydration and subsequent heat treatment. Since the amylose - amylopectin ratio was found to be less the uptake of water by the starches present in these rice varieties were minimum and contributed little to the structural degradation.

\section{Conclusion}

The structure of starch granule is influenced by fine structures and ratio of amylose and amylopectin molecules. Soaking and subsequent heat treatment will

Table 1. Amylose- Amylopectin ratio of raw and parboiled rice varieties

\begin{tabular}{|l|c|c|c|}
\hline Sample & $\begin{array}{c}\text { Total } \\
\text { Amylose (\%) }\end{array}$ & $\begin{array}{c}\text { Amylopectin } \\
(\%)\end{array}$ & $\begin{array}{c}\text { Amylose - Amylopectin } \\
\text { Ratio }\end{array}$ \\
\hline Raw D1 & 25.7 & 74.3 & 0.35 \\
\hline Raw Cheruvally & 25.2 & 74.8 & 0.34 \\
\hline Hot soaked D1 & 26.8 & 73.2 & 0.37 \\
\hline Hot soaked Cheruvally & 26.1 & 73.9 & 0.35 \\
\hline Cold soaked D1 & 27.8 & 72.2 & 0.39 \\
\hline Cold soaked Cheruvally & 27.7 & 72.3 & 0.38 \\
\hline
\end{tabular}




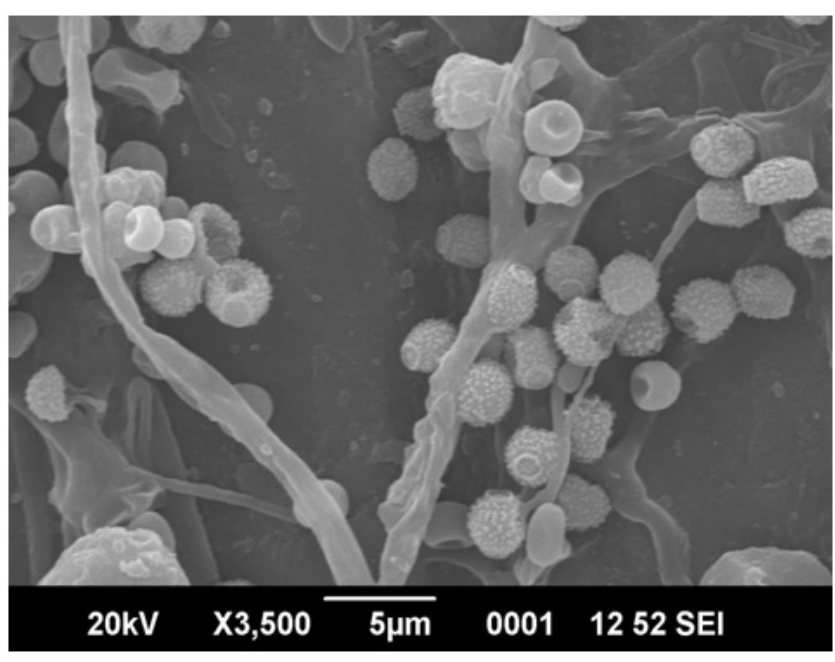

Figure 1. SEM micrograph of raw D1.

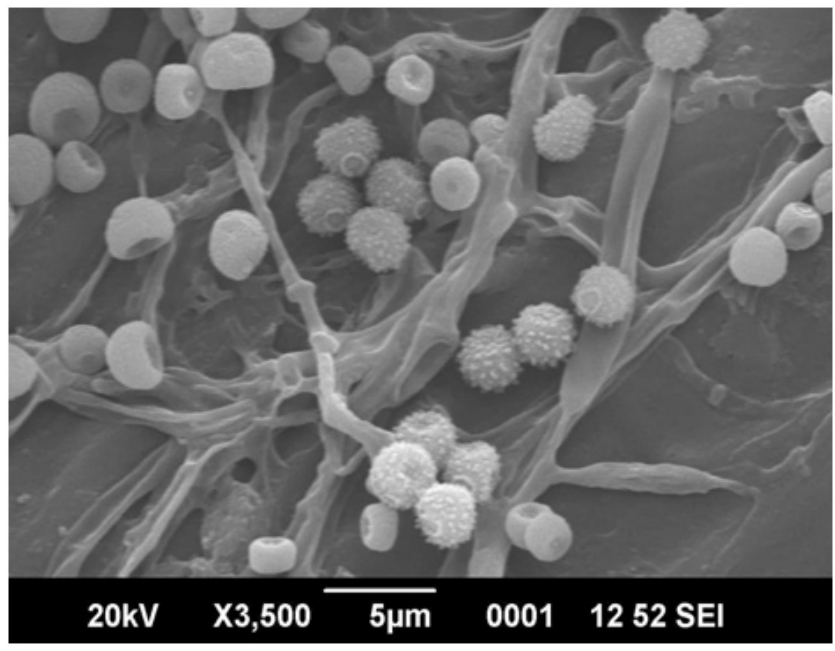

Figure 2. SEM micrograph of hot soaked D1.

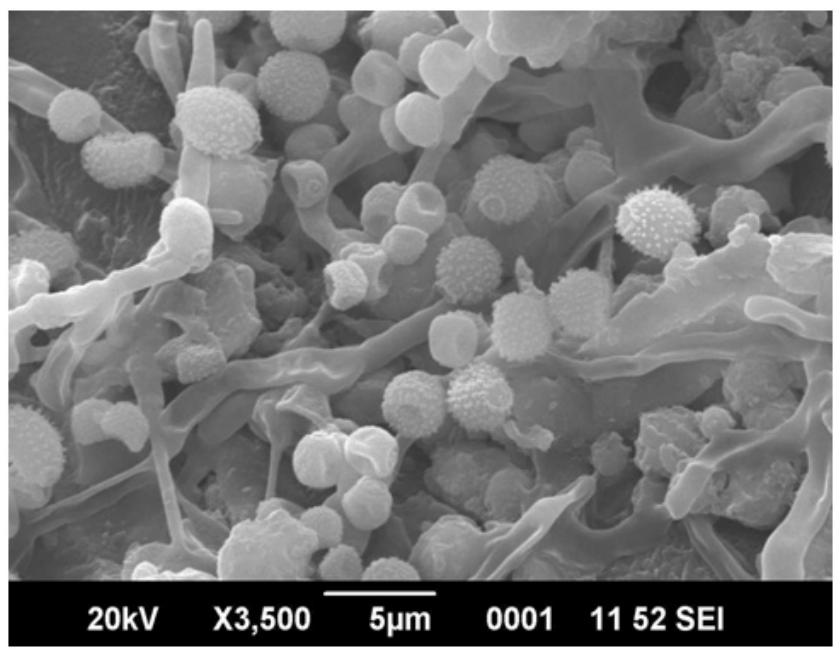

Figure 3. SEM Micrograph of Cold Soaked D1.

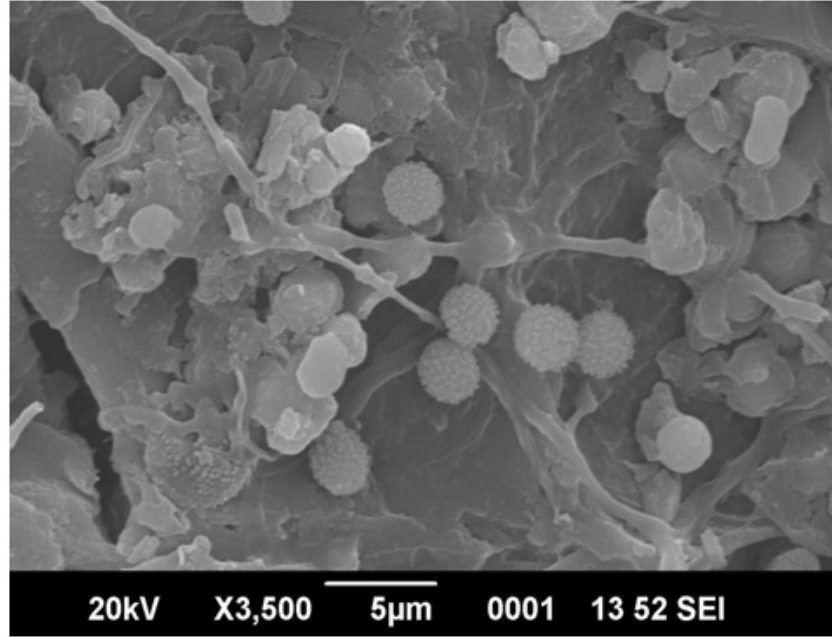

Figure 4. SEM Micrograph of Raw Cheruvally.

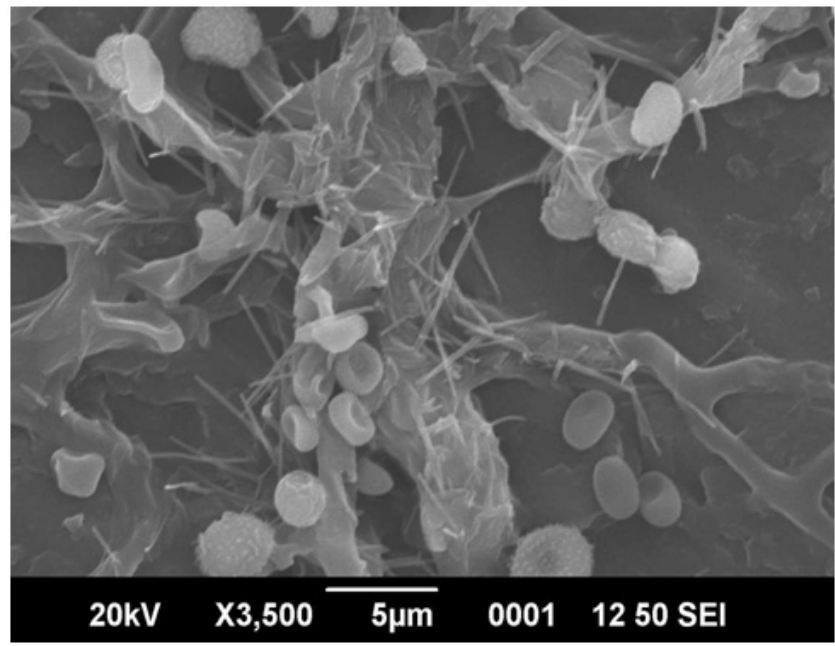

Figure 5. SEM Micrograph of Hot Soaked Cheruvally.

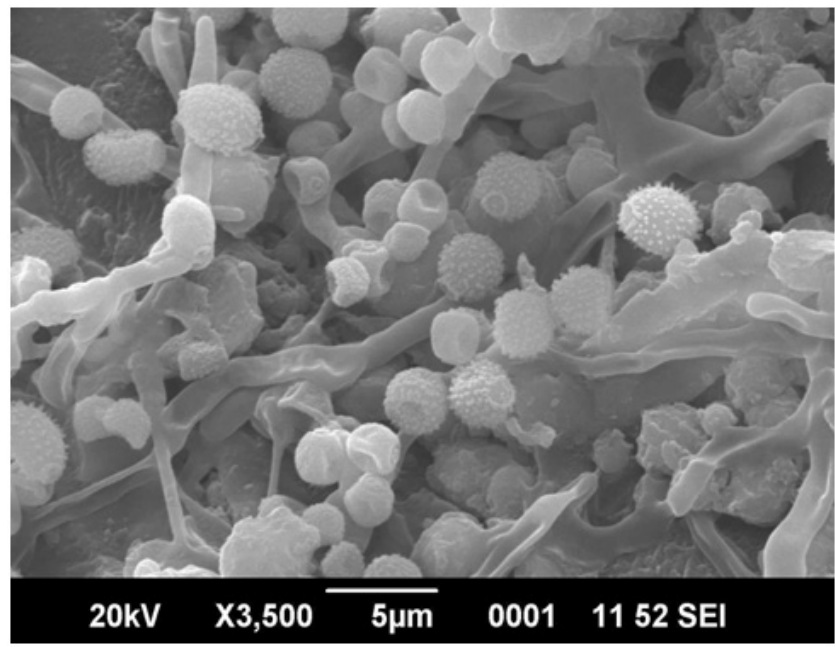

Figure 6. SEM Micrograph of Cold Soaked Cheruvally. 
also disrupt the highly ordered crystalline structure of the granule and results in decreased viscosity (pasting property). This difference in pasting property can be used to categorize the rice flours and its use in the production of industrially valuable products.

\section{References}

1. FAOSTAT, Agricultural statistical data, 2005. Available: www.faostat.fao.org

2. Lawal O. S., Lapasin R., Bellich B., Olayiwola T. O., Cesaro A., Yoshimura M., and Nishinari K. "Rheology and functional properties of starches isolated from five improved rice varieties from West Africa”, Food Hydrocolloids, vol. 25(7), p. 1785-1792, 2001.

3. Delcour J. A., Bruneel C., Derde L. J., Gomand S. V., Pareyt B., Putseys J. A., Wilderjans E., and Lamberts L. "Fate of starch in food processing: from raw materials to final food products", Food Science and Technology, vol. 1, p. 87-111, 2010.
4. Li J. H., Vasanthan T., Hoover R., and Rossnagel B. G. "Starch from hull-less barley: IV Morphological and structural changes in waxy, normal and high-amylose starch granules during heating", Food Research International, vol. 37, p. 417-428, 2004.

5. Hermansson M., and Svegmark K. "Developments in the understanding of starch functionality", Trends in Food Science and Technology, vol. 7, p. 345-353, 1996.

6. Tribess T., Hernandez-Uribe J., Mendez-Montealvo M., Menezes E., Bello-Perez L., and Tadini C. “Thermal properties and resistant starch content of green banana flour produced at different drying conditions", LWT-Food Science and Technology, vol. 42(5), p. 1022-1025, 2009.

7. Webb B. D. Rice quality and grade. Rice, Volume 2, Utilization. B. S. Luh, ed. Van Nostrand Reinhold, New York, 1991. p. 89-119.

8. Tan Y, Corke H. "Factor analysis of physicochemical properties of 63 rice varieties". Journal of the Science of Food and Agriculture, vol. 82, p. 745-752. 2002. doi: 10.1002/ jsfa. 1094 